\title{
Cholesterol Removal from Media by Lactococci
}

\author{
H. Kimoto, ${ }^{*}$ S. Ohmomo,† and T. Okamoto* \\ *Department of Animal Products, National Institute of Livestock and Grassland Science, \\ Tsukuba Norin-danchi, P.O. Box 5, Ibaraki 305-0901, Japan; and \\ †Japan International Research Center for Agricultural Sciences, 1-1, \\ Ohwashi, Tsukuba, Ibaraki 305-8686, Japan
}

\section{ABSTRACT}

Elevated serum cholesterol in humans is generally a risk factor correlated with the development of coronary heart disease. It has been reported that a culture of Lactobacillus acidophilus actively taking up cholesterol from a laboratory medium would function in vivo to exert a hypocholesterolemic effect. In the present study, seven strains of the genus Lactococcus were examined for their ability to remove cholesterol from laboratory media during growth. All strains of lactococci tested could remove cholesterol from media without degrading cholesterol. The amount of cholesterol removed was strain specific. Among them, Lc. Lactis subsp. lactis biovar diacetylactis N7 could remove as much cholesterol as L. acidophilus ATCC 43121, which had a beneficial influence on serum cholesterol levels in pigs. The manner of cholesterol removal by strain N7 corresponded to the manner of its growth. The growth of strain N7 (growth yield and growth efficiency) was enhanced. The fatty acid composition of the cells of strain N7 was altered by removing cholesterol from the media. The ability to remove cholesterol was also observed in the heat-killed cells of strain N7. However, the amount of cholesterol removed by the cells during growth was significantly higher than that removed by the heatkilled cells. Thus, strain N7 has the ability to remove cholesterol from media independently of whether cells are viable. These results indicate that administration of strain N7 in vivo may well be promising on the hypocholesterolemic effect.

(Key words: Lactococcus lactis, cholesterol removal, growth)

\section{INTRODUCTION}

In recent years, the probiotic activity of lactic acid bacteria has been emphasized. Probiotics are live microbial feed supplements which beneficially affect the host

Received February 16, 2002

Accepted April 27, 2002.

Corresponding author: H. Kimoto; e-mail: anne@niai.affrc.go.jp. animal by improving its intestinal microbial balance (Fuller, 1989). The most widely used probiotic lactic acid bacteria are lactobacilli and bifidobacteria that can survive in the intestine. Extensive studies on the beneficial effects on human health of these species have been reported (Perdigon et al., 1990; Benno et al., 1996).

In contrast, few studies exist on the probiotic activity of lactococci since they are traditionally not considered to be natural inhabitants of the human gastrointestinal tract (Teuber et al., 1992). However, several works showed the possibility of the presence of lactococci in the flora of the human or animal gastrointestinal tract (Gruzza et al., 1992; Grahn et al., 1994; Klijn et al., 1995). Our previous studies (Kimoto et al., 1999, 2000) also showed that some lactococci from dairy products tolerated specific conditions of the gastrointestinal tract such as low $\mathrm{pH}$ and bile. Lactococci are widely used as starter bacteria in manufacturing cheese and other fermented dairy products. Thus, establishing the effective probiotic properties of lactococci could lead to development of new probiotic foods.

One of the beneficial health effects related to probiotics is their ability to reduce serum cholesterol (Harrison and Peat, 1975; Grunewald, 1982). It has been reported that a culture of Lactobacillus acidophilus actively taking up cholesterol from laboratory media would function in vivo to exert a hypocholesterolemic effect (Gilliland et al., 1985; Danielson et al., 1989). For example, L. acidophilus ATCC 43121 can incorporate some of the cholesterol removed from media into the cellular membrane during growth (Noh et al., 1997), and it has beneficially influenced serum cholesterol levels (Gilliland et al., 1985; De Rodas et al., 1996). This is because cholesterol incorporated into or attached to cells of bacteria in the intestine is likely to be unavailable for absorption into the blood. The ability to incorporate cholesterol into or attach it to cells of bacteria has been equated with the ability to remove cholesterol from media. Many reports have been published on cholesterol removal from laboratory media containing bile and a cholesterol source in lactobacilli (Buck and Gilliland, 1994; Brashears et al., 1998; Usman and Hosono, 1999).

The present study was carried out to assess the cholesterol-removing ability of lactococci. 


\section{MATERIALS AND METHODS}

\section{Strains and Growth Conditions}

Lc. Lactis subsp. lactis biovar diacetylactis ATCC 13675 and $L$. acidophilus ATCC 43121 were from the American Type Culture Collection (Rockville, MD). The other strains in Tables 1 and 2 were from laboratory collections. L. acidophilus ATCC 43121 was used as a positive control (Noh et al., 1997). The strains were maintained by subculturing $1 \%$ inocula into M17 broth (Difco Laboratories, Detroit, MI) supplemented with $0.5 \%$ glucose (GM17) for lactococci or MRS broth (Difco) for L. acidophilus and incubating them for $18 \mathrm{~h}$ at $30^{\circ} \mathrm{C}$ for lactococci or at $37^{\circ} \mathrm{C}$ for $L$. acidophilus. The cultures were stored at $4^{\circ} \mathrm{C}$ between transfers and were subcultured one time before experimental use.

\section{Analysis of Cholesterol Removal from Media}

Freshly prepared GM17-THIO broth (GM17 broth with $0.2 \%$ sodium thioglycollate), MRS-THIO broth (MRS broth with $0.2 \%$ sodium thioglycollate), and GAM (Nissui, Tokyo, Japan) broth were supplemented with $0.2 \%$ sodium taurocholate (as a bile salt). Sodium thioglycollate was used as an oxygen scavenger (Gopal et al., 1996; Brashears et al., 1998; Usman and Hosono, 1999). GAM broth is used for the culture of anaerobic bacteria and originally contains sodium thioglycollate. A filter-sterilized cholesterol solution $(10 \mathrm{mg} / \mathrm{ml}$ in ethanol) was added to the broth to a final concentration of $70 \mu \mathrm{g} / \mathrm{ml}$. The broth was inoculated with $1 \%$ of culture and incubated anaerobically by using GasPak Anaerobic System (Becton Dickinson, Cockeysville, MD) for $24 \mathrm{~h}$ at $37^{\circ} \mathrm{C}$. Although the optimum temperature of lactococci is $30^{\circ} \mathrm{C}$, these experiments were carried out at $37^{\circ}$ to simulate the conditions of the intestine. After incubation, cells were removed by centrifugation for 7 $\min$ at $5,400 \times g$ and $4^{\circ} \mathrm{C}$. The method described by Rudel and Morris (1973) was used to determine the amounts of cholesterol in the spent broth and uninoculated broth. Subtracting the amount in the spent broth from that in the uninocualted broth yielded the amount removed by the cells.

The cell pellets from centrifugation were resuspended in distilled water to the original volume of the culture and were assayed for cholesterol.

\section{Changes in Cells by Removing Cholesterol during Growth}

Effect of cholesterol on growth. Lc. Lactis subsp. lactis bv. diacetylactis N7, selected as a most effective strain for removing cholesterol from media, was examined for further assays. Sterile cholesterol solution (i.e., with cholesterol) or ethanol (i.e., without cholesterol) was added to $50 \mathrm{ml}$ of GM17-THIO broth containing $0.2 \%$ sodium taurocholate. The medium was inoculated at $1 \%(\mathrm{vol} / \mathrm{vol})$ with a fresh overnight culturing of strain $\mathrm{N} 7$ and incubated anaerobically at $37^{\circ} \mathrm{C}$ for $24 \mathrm{~h}$. Aliquots $(5 \mathrm{ml})$ were taken from the broths every $3 \mathrm{~h}$ during culture for analyses (bacterial growth and the amount of cholesterol). Bacterial growth was determined by measuring the absorbance at $620 \mathrm{~nm}\left(A_{620 \mathrm{~nm}}\right)$ with a Spectronic 20 spectrophotometer (Bausch \& Lomb, Rochester, NY).

To determine growth efficiency, the molar growth yield from glucose (YG was calculated by dry weight (g) of the cells per mole of glucose consumed (Bauchop and Elsden, 1960). The $50 \mathrm{ml}$ of GM17-THIO broth, $50 \mathrm{ml}$ of GM17-THIO broth with $0.2 \%$ sodium taurocholate, and $50 \mathrm{ml}$ of GM17-THIO broth with $0.2 \%$ sodium taurocholate plus cholesterol were inoculated at $1 \%$ (vol/

Table 1. Cholesterol-removing ability and growth of lactococci. ${ }^{1}$

\begin{tabular}{llll}
\hline & \multicolumn{2}{c}{ Cholesterol } & \\
\cline { 2 - 3 } Culture & $\begin{array}{l}\text { Removed } \\
(\mu \mathrm{g} / \mathrm{ml})\end{array}$ & $\begin{array}{l}\text { Removal } \\
(\%)\end{array}$ & $\begin{array}{l}\text { Growth }^{2} \\
\left(A_{620)}\right.\end{array}$ \\
\hline Lactococcus lactis subsp. lactis & & & 1.08 \\
527 & 37.7 & 53.9 & 1.53 \\
G50 & 62.0 & 88.6 & 1.74 \\
H48 & 60.7 & 86.7 & \\
Lactococcus lactis subsp. lactis & & & 1.56 \\
biovar diacetylactis & 68.1 & 97.3 & 0.47 \\
N7 & 21.7 & 31.0 & 1.42 \\
ATCC 13675 & 41.0 & 58.6 & 0.31 \\
DRC1-F & 55.0 & 78.6 & \\
\hline
\end{tabular}

${ }^{1}$ Cells were incubated for $24 \mathrm{~h}$ at $37^{\circ} \mathrm{C}$ in GM17-THIO broth supplemented with $0.2 \%$ sodium taurocholate and cholesterol (final concentration in broth $=70 \mu \mathrm{g} / \mathrm{ml}$ ).

${ }^{2}$ The growth of each strain was measured after culture as absorbance at $620 \mathrm{~nm}$. All values are the means of two trials with duplicate. 
Table 2. Cholesterol removal by and growth of lactic acid bacteria in MRS-THIO and GAM broths.

\begin{tabular}{|c|c|c|c|c|c|c|}
\hline \multirow[b]{2}{*}{ Media } & \multicolumn{3}{|c|}{$\begin{array}{l}\text { Lactococcus lactis subsp. lactis } \\
\text { biovar diacetylactis N7 }\end{array}$} & \multicolumn{3}{|c|}{$\begin{array}{c}\text { Lactobacillus acidophilus } \\
\text { ATCC } 43121\end{array}$} \\
\hline & $\begin{array}{l}\text { Cholesterol } \\
\text { removed }^{1} \\
(\mu \mathrm{g} / \mathrm{ml})\end{array}$ & $\begin{array}{l}\text { Removal } \\
(\%)\end{array}$ & $\begin{array}{l}\text { Growth } \\
\left(A_{620}\right)\end{array}$ & $\begin{array}{l}\text { Cholesterol } \\
\text { removed }^{1} \\
(\mu \mathrm{g} / \mathrm{ml})\end{array}$ & $\begin{array}{l}\text { Removal } \\
(\%)\end{array}$ & $\begin{array}{l}\text { Growth } \\
\left(A_{620}\right) \\
\end{array}$ \\
\hline MRS-THIO & 20.6 & 29.4 & 1.70 & 37.0 & 52.9 & 1.34 \\
\hline GAM & 56.9 & 81.3 & 1.14 & 50.7 & 72.4 & 1.40 \\
\hline
\end{tabular}

vol) with a fresh overnight culture of strain N7, and incubated at $37^{\circ} \mathrm{C}$ for $24 \mathrm{~h}$. For measurements of dry weight, cells in the cultures were collected by centrifugation $(1800 \times g, 20 \mathrm{~min})$ at $4^{\circ} \mathrm{C}$, washed once with distilled water, and dried at $105^{\circ} \mathrm{C}$ for $4 \mathrm{~h}$. Residual glucose in the supernatant broth was measured enzymatically using the Glucose CII test kit Wako (Wako, Japan).

Cellular fatty acid composition of cells that removed cholesterol from media. GM17-THIO $(100 \mathrm{ml})$ with $0.2 \%$ sodium taurocholate plus ethanol (i.e., without cholesterol) and $0.2 \%$ sodium taurocholate plus cholesterol solution (i.e., with cholesterol) were prepared. The broths were inoculated with overnight culture at the $1 \%$ level and incubated at $37^{\circ} \mathrm{C}$. After $24 \mathrm{~h}$, the cultures were centrifuged at $1800 \times g$ for $20 \mathrm{~min}$ at $4^{\circ} \mathrm{C}$ and washed twice with distilled water. Free lipids were extracted from the pellets, and methyl esters were prepared by the method of Smittle et al. (1974). The methyl esters were separated on a gas chromatograph equipped with a flame ionization detector (HP5890; Hewlett-Packard, Avondale, PA). The oven temperature started at $75^{\circ} \mathrm{C}$ after a sample injection and was then increased linearly at $10^{\circ} \mathrm{C}$ per min up to $180^{\circ} \mathrm{C}$, after which it was increased $2^{\circ} \mathrm{C} / \mathrm{min}$ until the final temperature of $220^{\circ} \mathrm{C}$ was reached. The injector and detector temperatures were 240 and $230^{\circ} \mathrm{C}$, respectively. The fatty acid methyl esters were tentatively identified by comparing their retention times with known standards and were quantified using gas chromatographic equipment.

\section{Effect of Heat Treatment of Cells on Cholesterol Removal}

An overnight culture of strain N7 was inoculated into $10 \mathrm{ml}$ of GM17-THIO broth and incubated at $30^{\circ} \mathrm{C}$. After a 24-h incubation, the cells were harvested by centrifugation for $15 \mathrm{~min}$ at $1800 \times \mathrm{g}$, washed twice with distilled water, and resuspended in $10 \mathrm{ml}$ of distilled water. The suspension was divided into two portions. One was autoclaved for $15 \mathrm{~min}$ at $121^{\circ} \mathrm{C}$ for pre- paring heat-killed cells, and the other was not (i.e., resting cells). The heat-killed cells were suspended in GM17-THIO broth containing sodium taurocholate plus cholesterol previously adjusted at $\mathrm{pH}$ 6.8. In the case of the resting cells, they were suspended with 0.05 $M$ phosphate buffer ( $\mathrm{pH}$ 6.8) containing sodium taurocholate and cholesterol. The conditions of incubation and centrifugation were the same as described above. The spent broth was assayed for cholesterol.

\section{Statistical Analysis}

For statistical analysis, the standard error of the mean was calculated, and the means were tested according to Student's $t$-test for significant differences among the samples. A statistical significance was accepted at $P<0.05$.

\section{RESULTS}

\section{Removal of Cholesterol from Broth by Lactococci during Growth}

All lactococcal strains tested could remove cholesterol from GM17-THIO broth containing sodium taurocholate plus cholesterol during growth (Table 1). The amount of cholesterol removed was strain-specific. Among the strains tested, Lc. lactis subsp. lactis bv. diacetylactis N7 achieved the highest cholesterol removal (97\%). Cholesterol removed by the lactococcal strains tested was recovered with the resuspended cells (data not shown). Thus, cholesterol removed by the strains tested was not metabolically degraded.

L. acidophilus ATCC 43121 had been shown to beneficially influence serum cholesterol levels (Gilliland et al., 1985; De Rodas et al., 1996). We used L. acidophilus ATCC 43121 as a positive control (Noh et al., 1997). Table 2 shows a comparison of the amount of cholesterol removed by strain N7 with that by strain ATCC 43121 using two kinds of media. For the comparison, MRSTHIO and GAM broths but not GM17-THIO broth were used because L. acidophilus ATCC 43121 could not grow in GM17-THIO broth. In MRS-THIO broth, the 
amount of cholesterol removed by strain N7 was smaller than that by strain ATCC 43121. However, in GAM broth, strain N7 could remove a little more cholesterol than strain ATCC 43121.

In strains $\mathrm{N} 7$ and ATCC 43121, differences in ability to remove cholesterol were observed between the growth media used (Tables 1 and 2). As for strain N7, the amount of cholesterol removed was maximum in GM17-THIO broth and minimum in MRS-THIO broth among the growth media used. Tween 80 (sorbitan polyoxyethylene monooleate) is included in MRS broth $(0.1 \%)$ but not in GM17-THIO and GAM broths. To investigate the effect of Tween 80 on cholesterol removal, MRS-THIO and GM17-THIO broths with and without Tween 80 were prepared. In strain N7, the amount of cholesterol removed from MRS-THIO broth without Tween 80 was higher $(70 \mu \mathrm{g} / \mathrm{ml})$ than that removed from MRS-THIO broth with Tween $80(20.4 \mu \mathrm{g} /$ $\mathrm{ml}$ ). On the other hand, strain N7 removed cholesterol only very slightly when $1 \%$ Tween 80 was added to GM17-THIO broth $(6.0 \mu \mathrm{g} / \mathrm{ml})$, although its growth was good $\left(A_{620 \mathrm{~nm}}=2.16\right)$. In the case of strain ATCC 43121 , only a very small amount of cholesterol was removed when $1 \%$ Tween 80 was added to GM17-THIO broth $(8.67 \mu \mathrm{g} / \mathrm{ml})$, although its growth was good $\left(A_{620 \mathrm{~nm}}=\right.$ 3.29). In MRS-THIO broth without Tween 80, strain ATCC 43121 did not grow. This suggested that GAM broth, which omitted the effect of Tween 80, was adequate for a comparison of the amounts of cholesterol removed between these two strains.

\section{Changes in Cells by Removing Cholesterol during Growth}

Effect of cholesterol on growth. Figure 1 shows the growth curve of strain N7 and cholesterol removal during culture for $24 \mathrm{~h}$. The manner of cholesterol removal by strain N7 corresponded to the manner of its growth. The rapid cholesterol removal by strain N7 achieved during 12 to $18 \mathrm{~h}$ of incubation corresponded to its exponential growth phase. These data indicate that cholesterol removal was a result of the growth of strain N7 in broth containing cholesterol.

In the presence of cholesterol, strain $\mathrm{N} 7$ reached a higher cell density than in its absence (Figure 1). In fact, the dry weight of the cells growing in the absence and presence of cholesterol was 219 and $544 \mathrm{mg} / \mathrm{L}$, respectively. The growth rate of strain N7 growing in the presence of cholesterol was slightly higher than that in the absence.

Growth efficiency is expressed as molar growth yield from glucose YG. Strain N7 was inoculated into GM17THIO broth, GM17-THIO broth with sodium taurocholate, and GM17-THIO broth with sodium taurocholate

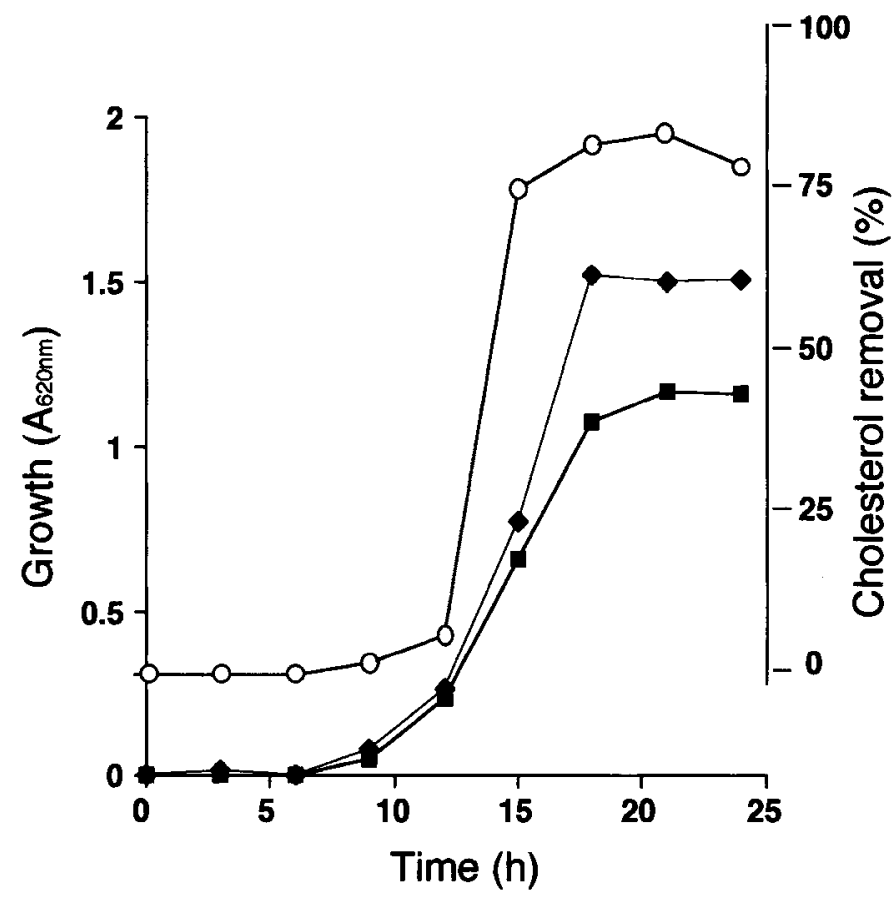

Figure 1. Cholesterol removal $(\bigcirc)$ by and growth in GM17-THIO broth containing sodium taurocholate (ם) and sodium taurocholate plus cholesterol ( ) of Lactococcus lactis subsp. lactis biovar diacetylactis N7. Values are means of two independent experiments performed in duplicate.

plus cholesterol. After cultivation for $24 \mathrm{~h}, \mathrm{YG}_{\mathrm{G}}$ was calculated (Table 3). YG for strain N7 grown in the presence of only sodium taurocholate was significantly $(P<0.01)$ lower than that for the control (i.e., no additions). When cholesterol was added to the broth containing sodium taurocholate, $\left(\mathrm{YG}_{\mathrm{G}}\right)$ significantly $(P<0.01)$ increased. However, the $\left(\mathrm{Y}_{\mathrm{G}}\right)$ value for cells grown with cholesterol was not the same as that for the control.

Effect of cholesterol on cellular fatty acid composition. The results from gas chromatographic analyses of free lipids extracted from cells of strain N7 grown with and without cholesterol are presented in Table 4.

Table 3. Effect of cholesterol and sodium taurocholate on molar growth yield from glucose $\left(\mathrm{Y}_{\mathrm{G}}\right)$ of Lactococcus lactis subsp. lactis biovar diacetylactis N7.

\begin{tabular}{lc}
\hline Additives for GM17 broth & $\left(\mathrm{YG}^{1}\right)$ \\
\hline None & $17.4(0.21)$ \\
Sodium taurocholate & $7.26(0.50)$ \\
Sodium taurocholate plus cholesterol & $12.6(0.59)^{* *}$ \\
\hline
\end{tabular}

${ }^{1}$ Strain N7 was cultured in GM17-THIO broth at $37^{\circ} \mathrm{C}$ for $24 \mathrm{~h}$.

${ }^{2}$ Dry weight per mole of glucose consumed. Values are means of four replications. Figures in parentheses represent SD values. Student's $t$ test was carried out on strain N7 with and without cholesterol.

$* * P<0.01$ 
Table 4. Fatty acid composition of Lactococcus lactis subsp. lactis biovar diacetylactis N7 grown in the presence and absence of cholesterol. ${ }^{1}$

\begin{tabular}{|c|c|c|}
\hline \multirow[b]{2}{*}{ Fatty acid $^{1}$} & \multicolumn{2}{|c|}{ Percentage of fatty acid of strain N7 grown } \\
\hline & Without cholesterol & With cholesterol \\
\hline $14: 0$ & $0.3(0.02)$ & $0.4(0.02)$ \\
\hline $16: 0$ & $22.7(0.33)$ & $20.7(0.34)^{* *}$ \\
\hline $16: 1$ & $2.9(0.10)$ & $3.0(0.05)$ \\
\hline $18: 0$ & $14.4(0.27)$ & $12.6(0.42)^{* *}$ \\
\hline $18: 1$ & $23.7(0.23)$ & $25.3(0.29)^{* *}$ \\
\hline $18: 2$ & $17.6(0.10)$ & $19.8(0.64)^{* *}$ \\
\hline$\triangle 19: 0$ & $2.6(0.12)$ & $2.8(0.10)$ \\
\hline Others & $15.6(0.52)$ & $15.5(1.05)$ \\
\hline
\end{tabular}

${ }^{1}$ Strain $\mathrm{N} 7$ grew in GM17-THIO broth containing $0.2 \%$ sodium taurocholate (without cholesterol) or containing $0.2 \%$ sodium taurocholate plus cholesterol (with cholesterol) at $37^{\circ} \mathrm{C}$ for $24 \mathrm{~h}$. Values are means of two trials with triplicate. Figures in parentheses represent SD values. Student's $t$-test was carried out on strain N7 with and without cholesterol.

${ }^{2}$ Fatty acid methyl esters are designated by the number of carbon atoms to the left of the colon and the number of double bonds to the right.

**Significantly different from without cholesterol. $P<0.01$.

There was a difference in the fatty acid distribution pattern for cells grown with and without cholesterol. In the presence of cholesterol, the cells contained significantly $(P<0.01)$ more octadecenoic and octadecadienoic and less hexadecanoic and octadecanoic acids than the cells grown without cholesterol. Total saturated (SFA) and unsaturated (UFA) fatty acids from the cells grown without cholesterol were 37.4 and $46.8 \%$, respectively. In the presence of cholesterol, total SFA and UFA were 33.7 and $50.9 \%$, respectively.

\section{Effect of Heat Treatment of Cells on Cholesterol Removal}

We determined whether even dead cells of strain N7 could remove cholesterol. The heat-killed cells were suspended in GM17-THIO broth containing sodium taurocholate plus cholesterol adjusted to $\mathrm{pH}$ 6.8. After incubation for $24 \mathrm{~h}$ at $37^{\circ} \mathrm{C}$, cholesterol removal from GM17THIO broth by the heat-killed cells was observed (Figure 2). The amount of cholesterol removed by the heatkilled cells was the same as that by resting cells (i.e., not heat-killed cells). This indicated that the ability to remove cholesterol from media did not decrease due to heat treatment. The amount of cholesterol removed by the cells during growth (i.e., growing cells) was significantly $(P<0.05)$ higher than that removed by heatkilled and resting cells.

\section{DISCUSSION}

A high level of cholesterol in blood is generally considered to be a risk factor for coronary heart disease. The effects of ingestion of probiotic bacteria such as L. acidophilus on serum cholesterol levels have attracted much interest in recent years. The effect of $L$. acidophilus on serum cholesterol levels is thought to relate to its ability to take up cholesterol from media during growth (Gilliland et al., 1985; Danielson, et al. 1989). While reports

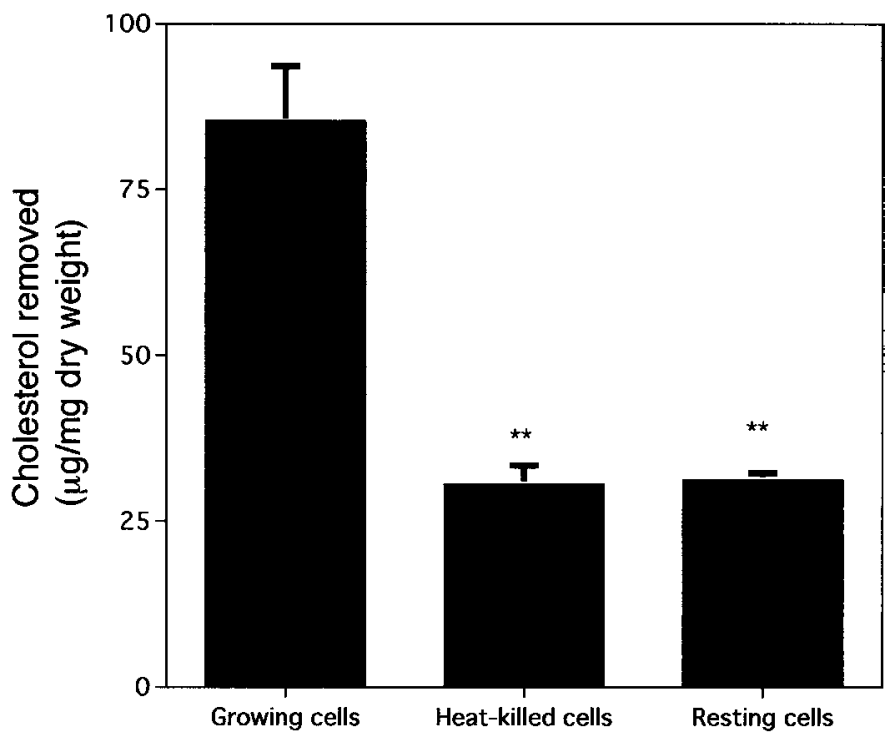

Figure 2. Cholesterol removal by growing, heat-killed, and resting cells of Lactococcus lactis subsp. lactis biovar diacetylactis N7. Cell mass was determined from a standard curve relating optical density to dry weight to calculate relative amounts of cholesterol removed ( $\mu \mathrm{g} / \mathrm{mg}$ dry weight). Cells that removed cholesterol from the media during growth for $24 \mathrm{~h}$ at $37^{\circ} \mathrm{C}$ were designated as growing cells. The heat-killed cells of strain N7 were prepared by autoclaving for 15 min at $121^{\circ} \mathrm{C}$ and were suspended in GM17-THIO broth containing sodium taurocholate plus cholesterol. Resting cells were suspended in $0.05 \mathrm{M}$ phosphate solution. These cell suspensions were incubated at $37^{\circ} \mathrm{C}$ for $24 \mathrm{~h}$. Values are means $\pm \mathrm{SD}$ of two independent experiments performed in duplicate. ** Significantly different from growing cells, $P<0.01$. 
of the ability of lactobacilli are numerous (Buck and Gilliland, 1994; Noh et al., 1997; Brashears et al., 1998), few reports have been published concerning this ability in lactococci. In the present study, we have shown that all the strains of lactococci tested had the ability to remove cholesterol from laboratory media during growth. Among the strains tested, Lc. lactis subsp. lactis biovar diacetylactis $\mathrm{N} 7$ could remove as much cholesterol as L. acidophilus ATCC 43121 (Tables 1 and 2). L. acidophilus ATCC 43121 is an isolate from the intestine of a pig and has been shown to beneficially influence serum cholesterol levels in pigs (Gilliland et al., 1985). Administration of strain N7 in humans will be needed to assess the effect of strain N7 on serum cholesterol levels.

When strain N7 is administered in vivo, it is exposed to enzymes in the oral cavity (e.g., lysozyme) and to the digestive process in the stomach and the intestinal tract. Our previous in vitro studies showed that strain N7 had a good chance to survive in the gastrointestinal tract (Kimoto et al., 2000). Thus, strain N7 is to be expected for survival in the intestine and removing cholesterol. Furthermore, cholesterol removal from media at $\mathrm{pH} 6.8$ by heat-killed cells of strain N7 was also observed (Figure 2). The physiological $\mathrm{pH}$ in the intestinal tract of humans is usually neutral to alkaline (Fordtran and Locklear, 1966). Thus, administration of strain N7 in vivo would have the potential to reduce cholesterol concentration in the intestine independently of whether cells are viable.

The mechanism by which lactic acid bacteria remove cholesterol from laboratory media has been studied. It has been reported (Klaver and Van der Meer, 1993) that cholesterol removal by some lactobacilli is only due to a disruption of the cholesterol micelles caused by the deconjugation and precipitation of cholesterol with the free bile salts as the $\mathrm{pH}$ of the media dropped by acid production during growth. We confirmed that strain N7 and other lactococci did not produce cholic acid from sodium taurocholate (data not shown). This suggested that cholesterol removal by the lactococci tested was not related to the precipitation of cholesterol with free bile salts.

There are two possible mechanisms underlying the ability of lactococci to remove cholesterol from media. One is adhesion of the cholesterol to the cell surface. Hosono and Tono-oka (1995) have reported that lactic acid bacteria, including lactococci, bind cholesterol to the cells. In their study, the cholesterol-binding ability was studied by mixing cholesterol solution in $60 \%$ ethanol with the lyophilized cells. As a result, they suggested that binding of cholesterol to the cells may be a physical phenomenon and be related to the cell wall. The other possible mechanism is an assimilation of cho- lesterol by the cells. It was reported that some strains of $L$. acidophilus incorporated some of the cholesterol into the cellular membrane (Noh et al., 1997; Brashears et al., 1998). In the present study, the mechanism by which Lc. lactis subsp. lactis biovar diacetylactis N7 removed cholesterol from media during growth is clear to some extent. Because even the heat-killed cells of strain N7, which cannot take up cholesterol, could remove it from media (Figure 2), it seemed that some cholesterol had bound to the cells. Figure 2 also shows that the amount of cholesterol removed by strain N7 during growth (as growing cells) was higher than that by the heat-killed cells, suggesting that the difference in the amount of cholesterol removed between the heatkilled cells and growing cells was due to the uptake of cholesterol by strain N7. Thus, it seems that strain N7 can remove cholesterol from media both by binding of cholesterol to dead cells and by the uptake of cholesterol into living cells during growth. It is likely that the mechanism of cholesterol removal in strain N7 applies to that of other lactocococi tested.

So far it has been reported that lactococci could bind cholesterol in 60\% ethanol solution (Hosono and Tonooka, 1995). However, the growth of lactococci was not considered in that study because lactococci cannot grow in $60 \%$ ethanol solution. In the present study, we focused on cholesterol removal by lactococci during growth. In strain N7, the manner of cholesterol removal corresponded to the manner of its growth (Figure 1). This result indicates that cholesterol removal by strain N7 was a result of its growth in the broth containing cholesterol. Furthermore, it is worth noting that the growth of strain N7 was stimulated by removing cholesterol from the media, thus enhancing the growth yield of strain N7 (Figure 1). The growth efficiency of strain N7 was also enhanced (Table 3 ). These results indicate that cholesterol removal, far from being harmful to strain N7, was actually beneficial to it. Although the reason is not clear at this moment, it seems that changes occur in the cells as a result of removing cholesterol from the media. In fact, there was a difference in the fatty acid distribution pattern for cells grown with and without cholesterol (Table 4). The lipids of Grampositive bacteria are found predominantly in the membrane, suggesting that cholesterol removed from media by strain N7 was incorporated into the cellular membrane and may have altered the fatty acid composition of the cells.

In conclusion, the lactococcal strains tested could remove cholesterol from media during growth. Among them, Lc. lactis subsp. lactis biovar diacetylactis N7 could remove the most cholesterol and could do so independently of whether cells are viable. These results 
indicate that strain N7 may be a promising candidate for strain for use as a probiotic strain.

\section{REFERENCES}

Bauchop, T., and S. R. Elsden. 1960. The growth of micro-organisms in relation to their energy supply. J. Gen. Microbiol. 23:457-469.

Benno, Y., F. He, M. Hosoda, H. Hashimoto, T. Kojima, K. Yamazaki, H. Iino, H. Mykkanen, and S. Salminen. 1996. Effects of Lactobacillus GG yogurt on human intestinal microecology in Japanese subjects. Nutr. TODAY Supplement 31:9S-11S.

Brashears, M. M., S. E. Gilliland, and L. M. Buck. 1998. Bile salt deconjugation and cholesterol removal from media by Lactobacillus casei. J. Dairy Sci. 81:2103-2110.

Buck, L. M., and S. E. Gilliland. 1994. Comparisons of freshly isolated strains of Lactobacillus acidophilus of human intestinal origin for ability to assimilate cholesterol during growth. J. Dairy Sci. 77:2925-2933.

Danielson, A. D., E. R. Peo Jr., K. M. Shahani, A. J. Lewis, P. J. Whalen, and M. A. Amer. 1989. Anticholesteremic property of Lactobacillus acidophilus yogurt fed to mature boars. J. Anim. Sci. 67:966-974.

De Rodas, B. Z., S. E. Gilliland, and C. V. Maxwell. 1996. Hypocholesterolemic action of Lactobacillus acidophilus ATCC 43121 and calcium in swine with hypercholesterolemia induced by diet. J. Dairy Sci. 79:2121-2128.

Fordtran, J. S., and T. W. Locklear. 1966. Ionic constituents and osmolality of gastric and small-intestinal fluids after eating. Am. J. Dig. Dis. 11:503-521.

Fuller, R. 1989. Probiotics in man and animals. J. Appl. Bacteriol. 66:365-378.

Gilliland, S. E., C. R. Nelson, and C. Maxwell. 1985. Assimilation of cholesterol by Lactobacillus acidophilus. Appl. Environ. Microbiol. 49:377-381.

Gopal, A., N. P. Shah, and H. Roginski. 1996. Bile tolerance, taurocholate deconjugation and cholesterol removal by Lactobacillus acidophilus and Bifidobacterium spp. Milchwissenschaft 51:619-623.

Grahn, E., S. E. Holm, H. Lilja, and K. Sellgren. 1994. Interference of a Lactococcus lactis strain on the human gut flora and its capacity to pass the stomach and intestine. Scand. J. Nutr. 38:2-4.

Grunewald, K. K. 1982. Serum cholesterol levels in rats fed skim milk fermented by Lactobacillus acidophilus. J. Food Sci. 47:2078-2079.
Gruzza, M., Y. Duval-Iflah, and R. Ducluzeau. 1992. Colonization of the digestive tract of germ-free mice by genetically engineered strains of Lactococcus lactis: study of recombinant DNA stability. Microb. Releases 1:165-171.

Harrison, V. C., and G. Peat. 1975. Serum cholesterol and bowel flora in the new born. Am. J. Clin. Nutr. 28:1351-1355.

Hosono, A., and T. Tono-oka. 1995. Binding of cholesterol with lactic acid bacterial cells. Milchwissenschaft 50:556-560.

Kimoto, H., J. Kurisaki, N.-M. Tsuji, S. Ohmomo, and T. Okamoto. 1999. Lactococci as probiotic strains: adhesion to human enterocyte-like Caco-2 cells and tolerance to low $\mathrm{pH}$ and bile. Lett. Appl. Microbiol. 29:313-316.

Kimoto H., S. Ohmomo, M. Nomura, M. Kobayashi, and T. Okamoto. 2000. In vitro studies on probiotic properties of lactococci. Milchwissenschaft 55:245-249.

Klaver, F. A. M., and R. Van der Meer. 1993. The assumed assimilation of cholesterol by lactobacilli and Bifidobacterium bifidum is due to their bile salt-deconjugating activity. Appl. Environ. Microbiol. 59:1120-1124.

Klijn, N., A. H. Weerkamp, and W. M. de Vos. 1995. Genetic marking of Lactococcus lactis shows its survival in the human gastrointestinal tract. Appl. Environ. Microbiol. 61:2771-2774.

Noh, D. O., S. H. Kim, and S. E. Gilliland. 1997. Incorporation of cholesterol into the cellular membrane of Lactobacillus acidophilus ATCC 43121. J. Dairy Sci. 80:3107-3113.

Perdigon, G., S. Alvarez, M. E. N. de Macias, M. E. Roux, and A. P. de Ruiz Holgado. 1990. The oral administration of lactic acid bacteria increase the mucosal intestinal immunity in response to enteropathogens. J. Food Prot. 53:404-410.

Rudel, L. L., and M. D. Morris. 1973. Determination of cholesterol using o-phthalaldehyde. J. Lipid Res. 14:364-366.

Smittle, R. B., S. E. Gilliland, M. L. Speck, and W. M. Walter Jr. 1974. Relationship of cellular fatty acid composition to survival of Lactobacillus bulgaricus in liquid nitrogen. Appl. Microbiol. 27:738-743.

Teuber, M., A. Geis, and H. Neve. 1992. The genus Lactococcus. Pages 1482-1501 in The Prokaryotes. Vol. II. 2nd. ed. A. Balows, H. G. Truber, M. Dworkin, W. Harder, and K. H. Schleifer, ed. Springer Verlag, New York, NY.

Usman, and A. Hosono. 1999. Bile tolerance, taurocholate deconjugation, and binding of cholesterol by Lactobacillus gasseri strains. J. Dairy Sci. 82:243-248. 